\title{
Textbook Evaluation: A Case Study of Punjab, Pakistan
}

\author{
Muhammad Imtiaz Shahid, ${ }^{1 *}$ Hafiz Muhammad Qasim, ${ }^{2}$ \\ Muhammad Javed Iqbal ${ }^{3}$
}

${ }^{1}$ Higher Education Department, Government of Punjab, Pakistan, ${ }^{2}$ Department of Applied Linguistics, Faculty of Social Sciences, Government College University Faisalabad, Pakistan, ${ }^{3}$ Centre for Languages and Translation Studies, University of Gujrat, Pakistan

$\left.{ }^{*}\right)$ Corresponding Author

Email imtiazrai501@gmail.com

DOI: $10.18326 /$ rgt.v14i2.283-300

\section{Submission Track:}

Received: 28-08-2021

Final Revision: 01-12-2021

Available Online: 05-12-2021

Copyright (C) 2021 Author(s)

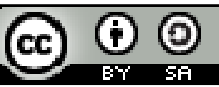

This work is licensed under a Creative Commons Attribution-ShareAlike 4.0 International License.

\begin{abstract}
Textbook is one of the most substantial elements of classroom learning. As a result, it is critical to conduct a textbook evaluation to improve the quality of the teaching and learning environment in the classroom. Keeping in mind the very importance of the textbook evaluation, the current study evaluated a 10th-grade English textbook published by Punjab Curriculum and Textbook Board Lahore, Pakistan. The present study aimed to evaluate the book's overall pedagogical worth according to teachers' and students' needs and demands. For this purpose, 10 teachers and 60 students were selected from different public and private schools. Two different questionnaires were prepared by Litz (2001) with slight variations. The teachers' questionnaire version had 20 items, while the students' version had 15 items. The statistical analysis was carried out using SPSS after the data had been collected. The study's findings revealed that the textbook as a whole is well-designed and offers an array of useful extra materials. The book is also visually pleasing, well-organized, consistent, and orderly. Overall, the positive characteristics outnumbered the negative ones by a wide margin. Despite a few flaws in the book, such as the lack of a glossary and grammar, the results showed that the textbook was adequate for language learners. Overall, it was considered that, despite some flaws, the textbook fulfilled the needs of students and might be a practical book in the hands of competent teacher.
\end{abstract}

Keywords: textbook; evaluation; English language 


\section{INTRODUCTION}

One of the most important instruments for classroom learning is textbook. Textbooks have historically been regarded as the most important tool for applying school curricula (Hutchinson \& Torres, 1994). Textbooks play an important role in classroom instruction and student development (Serasi, et al., 2021; Daneshfar \& Abdollahi, 2018). They have an enormous influence on both teaching and learning. Sheldon (1988) claims that textbooks constitute the heart and soul of any topic. A textbook comprises content carrying material to mold and modify the ideologies, values and behaviors of learners (Mahmood et al., 2021).

Despite technological advances that allow for higher-quality teachergenerated texts, the need for textbooks continues to grow, and the publishing industry reacts by introducing new series and textbooks year after year. Many learners who use a textbook, according to Razmjoo (2007), feel safe, make progress and accomplish their goals. Textbooks are a viable tool for selfdirected study, an appropriate instrument for teachers disseminating lessons, a repository of thoughts and actions, a reference source for learners, and a curriculum that incorporates preset educational goals, according to Cunningsworth (1995).

When selecting a textbook for a language class, there are several factors to take into account. According to Romero (1975), an excellent English textbook should include these characteristics: A) The textbook objectives should be clear and attainable; B) it should be issued in series; C) the textbook should be visually appealing; D) lessons should be brief and well-structured; E) the material should be engaging for the pupils who will be using it; F) exercises should be kept to a minimum and short; and G) a suitable textbook could come with a teacher's guide.

Choosing the right textbook is a difficult task; there are a plethora of books on the market with grandiose claims made by publishers and writers. Many English textbooks have numerous theoretical faults, design defects, and practical concerns (Litz, 2005). They contain disconnected information that is not connected between chapters. As a result, every teacher should choose their language textbooks carefully. Additionally, it is vital to examine a textbook in 
order to determine its true value and wattage for language learners of any language. Sheldon (1988) states that choosing an ELT textbook is typically a significant administrative and educational decision involving significant professional, monetary, and even political involvement. As a result of a thorough examination, a school or institution's administration and teachers would indeed be able to tell the difference between all the available textbooks on the market.

Dickens and Germaine (1992) argue that evaluation is a lively process of evaluating the applicability and adequacy of a phenomenon. As an innate predisposition in producing advancements and alterations within the teaching and learning environment, it is a beneficial tool for instructors and textbooks' authors alike (Ayu \& Indrawati, 2019). Regardless of its importance in enhancing different parts of teaching environment, assessment is still a poorly articulated and endorsed component of many projects (Hargreaves, 1989). As a result, the textbook's importance as a fundamental cornerstone of English language teaching (ELT) is evident (Hutchison \& Torres, 1994).

There has been a growth in the number of global commercial English textbooks published by major publishers. This indicates a wide range of consumers' requests for a custom-designed textbook that meets their specific requirements. Crawford (2002) also advocates that good course books should be critically reviewed, taking into account both their limitations and their promises. Moreover, English is taught to children in public schools, private schools, and other language institutes throughout Pakistan. Faced with the reality that English textbooks play an essential function in acquisition of the English language (Ponnusamy, Sandaran \& Gunasegaran, 2021), the present research study looks into and evaluates one of the textbooks that is used in public and private schools of Punjab, Pakistan to examine how well it meets the demands of students and teachers.

The purposes of the research were to find answers to the questions of knowing the extent of the textbook acceptable in terms of practical consideration (price, availability, and presentation), the extent of the textbook acceptable in terms of its layout and design, whether the textbook provide a balance of conducive and sufficient activities, whether the textbook contains 
sufficient material related to all four language skills, whether the subject and content of the textbook relevant to learners' needs.

\section{LITERATURE REVIEW}

The field of textbook evaluation is well-established; many research investigations have been undertaken at various levels around the world. Different academics have assessed the usefulness of numerous textbooks from diverse angles. Badawi (2007) assessed the content of a 10th-grade English textbook that is provided to Palestinian students in Palestine. The descriptiveanalytical method was employed to perform the research investigation. To collect data, an analysis card was created. These data included conducting a textbook survey to examine the activities that met the study criteria. The findings of this study indicated that communication was the most important factor in the textbook under consideration. In the book, the relationships between groups and cultural norms were the least prominent. The researcher concluded that the distribution of standards among the various textbook units should be balanced.

Kirkgöz (2009) presented a review of three English textbooks used in primary schools in Turkey. These are the books which are used by the Turkish Ministry of National Education. A questionnaire was used to collect input from students and teachers. A total of 37 questions were included in the survey. Students and teachers were also questioned in order to learn more about how the books were used. The analysis demonstrated the extent to which the three textbooks taught to young English students were adequate. The study offers many recommendations and suggestions for the future revisions of the textbooks which would be very helpful in meeting the needs of young students.

Marc and Rees (2009) looked into the content of textbooks as well as how they were used by teachers. The findings of the study revealed that author depiction in textbooks is more resembling students' reading tastes rather than literary experts' choices. Simultaneously, teachers are increasingly adopting textbooks that prioritize students' desires. These patterns occur as a consequence of changes in the student population rather than the instructor characteristics. 


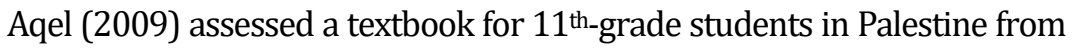
the standpoint of a teacher. The researcher created an evaluation scale to evaluate the performance of the textbook under consideration. The study sample included 60 teachers, both male and female. To review the book, Aqel created a 47-item questionnaire and examined four domains in the questionnaire. The study's findings revealed a moderate outcome; the book is skewed in favor of female educators. According to the findings, English textbooks should be changed every year.

Fukkink (2010) evaluated textbooks, which are taught to students in the Dutch educational system, from the perspective of content analysis. The research revealed anomalies in the curriculum design. The study findings demonstrated that content standards do not correspond to teachers' requirements. It was also discovered that the textbooks do not meet the standard requirements. Teachers' responsibilities have received a lot of attention in textbooks rather than strategic planning, development, educational policy, and collaboration with peers from other fields.

Mohammadi and Abdi (2014) investigated one of Iran's most prestigious textbooks. Their goal was to establish whether or not the book was adequate and suitable for the students' needs. They collected data from 137 participants (105 students and 32 teachers). The information was gathered using a questionnaire created by Litz (2021). There were two separate questionnaires created. The teacher's questionnaire had 40 questions, whereas the student's questionnaire had 25. They concluded that the reviewed textbook is adequate and appropriate for the pupils after assessing the facts. They also came to the conclusion that it may be a good book in general in the hands of teachers.

Suhirman (2018) analyzed an ESP textbook and presented an evaluation of the English textbook, English for Islamic Learning: For College Students. The impetus of this study was to check the appropriateness of the book. It dealt with the question of how well this book meets the needs of the English language students. The textbook was evaluated from the perspective of its contents, presentations, strategies, students' needs, and interests. Twenty students and one teacher contributed in this research study. Questionnaire, which consisted of 10 items, was used to collect the data from the participants. After the detailed 
analysis of the data, the study concluded that although the evaluated textbook had deficiencies from different perspectives, it has satisfied the requirements and needs of the English language learners.

Surtikanti (2020) evaluated a newly assigned coursebook When English Rings A Bell. After collecting and analyzing the collected data, the researcher claimed that the textbook has shortcomings. The study findings pointed out that the textbook does not cover four basic skills of the English language. It was discovered that the book does not follow the scientific approach of teaching. According to the results of the study, the book does not offer quality contents for English language learners.

Rahim et al. (2021) did a research study in Afghanistan to evaluate English textbooks. To analyse a 12th-grade book, the researchers utilised a mixedmethod technique. The information was gathered using a checklist that was created using a Likert scale. SPSS was used to examine the data which was collected through checklist. The study findings revealed that the evaluated contents did not meet the objectives of a teaching program. They are incompatible with the demands of the students. The textbook includes all four skills of language acquisition, according to the research, although there is a strong emphasis on reading, grammar, and vocabulary. Overall, the research found that the textbook should be changed and upgraded to satisfy the demands of students.

Serasi et al. (2021) conducted research based on the perception of the teacher and students in Madrasah Ibtidaiyyah (MI) Nurul Huda Bengkulu City. The study aimed to assess the suitability of the book. This study used a quantitative research approach. The total population of this study was 114 students and 1 English teacher. In collecting data, researchers used a checklist as the instrument adapted from Demir and Ertas. The research utilizeda checklist to collect data for their research study. The results of the current study revealed that both textbooks matched the criteria for good EFL textbooks, which included the availability of materials based on subjects and contents, skills and sub-skills, and layout.

After taking stock of literature on textbook evaluation, it is concluded that textbook evaluation is one of the most important fields of inquiry. Different studies have been conducted in different parts of the world. It has become 
apparent from the review of previous studies that textbook evaluation has very dominant and strong effects in updating the ongoing system. Hence it has become very important to evaluate its suitability and appropriateness at the school level. So, this study is designed to evaluate English textbook which is taught to 10th grade in Punjab, Pakistan.

\section{RESEARCH METHOD}

\section{Participants}

The present study included both students and teachers as its participants. Ten teachers and 60 students, who were teaching and studying 10th grade English textbooks, published by Punjab Curriculum and Textbook Board Lahore, Pakistan, contributed in the present research study. The respondents belong to both public and private sectors. The teachers had taught the abovesaid textbook for more than three years on average. The students were the students of 10th grade. The students varied in age from 14 to 17 . They were all in high school at the time.

\section{Instrument}

To get data from the students and teachers questionnaires were used. Two questionnaires were designed by the research using Litz (2001), with a slight variation keeping in mind the background and level of the participants. Questions of the questionnaire were changed to the Likert scale instead of the semantic differential scale to make it easy for the students. Questionnaires were handed over to the participants personally, who filled and returned them to the researcher then and there.

\section{Data Collection and Analysis}

Both questionnaires, 01 belonging to teachers and 01 belonging to students, were administered during class time to students and teachers for the collection of the data. Dimensions and sub-dimensions of the questionnaire were explained well to understand their meanings and purpose. To obtain valid results, the participants were given a choice to fill the questionnaire voluntarily. The researcher was successful in collecting all the copies of the questionnaire from students and teachers. 


\section{Table 1}

Dimensions of the Questionnaires

\begin{tabular}{llll}
\hline \multirow{2}{*}{ Sr. No. } & \multirow{2}{*}{ Dimensions (Questions) } & \multicolumn{2}{l}{ No. of Sub-questions } \\
\cline { 3 - 4 } & & Teachers & Students \\
\hline 1 & Practical Considerations & 02 & 02 \\
2 & Layout \& Design & 03 & 02 \\
3 & Activities & 03 & 02 \\
4 & Skills & 02 & 02 \\
5 & Language Type & 03 & 02 \\
6 & Subject \& Content & 04 & 03 \\
7 & Conclusion & 03 & 02 \\
\hline & Total & 20 & 15 \\
\hline
\end{tabular}

After the collection of the instrument, it was collected for data analysis. The copies of the questionnaires were analyzed statistically. The means of the teachers and students in every single item were calculated using SPSS and summarized the teachers' and students' views about the evaluated textbook.

\section{RESULTS \& DISCUSSION}

\section{Practical Consideration}

This section of the questionnaires contained 02 items, both for the teachers and students. In this part of the questionnaire, the dominant factor which forced students and teachers to choose the book was its cost. The statistics revealed that the majority of the respondents chose A (agree) or SA (strongly agree) regarding the book's price. According to Litz (2001), the cost is an essential factor in choosing a textbook.

Regarding the accessibility of the book, teachers' means was 3.3 and students' means was 3.1. It may be because the book was only available in the big cities and teachers and students cannot find it easily in their hometown. According to Mohammadi and Abdi (2014), the availability of the textbooks affects the selection of textbooks. A textbook, for example, must be in print and widely available in order to be purchased (Litz, 2001).

\section{Layout and Design}

Arrangement and presentation of the contents and discussed topics are part of the design and layout of a textbook (Mohammadi \& Abdi, 2014; Litz, 
2001). The findings of the study demonstrated that the majority of the teachers and students were pleased with the overall arrangement and designing of the $10^{\text {th }}$-grade textbook published by Punjab Curriculum and Textbook Board Lahore, Pakistan. The learning objectives of each unit are clear and concise. The textbook is designed according to the needs and levels of the students. It has examples and pictures to explain the complex parts, which give the book an exciting look. The vocabulary lists are very helpful for students and teacher because they provide additional aids which help students and teachers to understand the discussed content easily and accurately.

\section{Table 2}

Summary of the Responses Regarding Layout and Design

\begin{tabular}{llll}
\hline Sr. No. & Question & Teachers & Students \\
\hline 3 & $\begin{array}{l}\text { The layout and design are } \\
\text { appropriate and clear. }\end{array}$ & $* \mathrm{~A}$ & $* \mathrm{~A}$ \\
4 & $\begin{array}{l}\text { The textbook is organized } \\
\text { effectively. }\end{array}$ & $*$ SA & $* \mathrm{~A}$ \\
\hline
\end{tabular}

Note: ${ }^{*} \mathrm{~A}=$ Agree, ${ }^{* *} \mathrm{SA}=$ Strongly Agree

While the general design was excellent, the statistics of data revealed that an appropriate collection of assessment quizzes or testing recommendations was not supplied. It indicates that students are not given enough chances to assess themselves. Simultaneously, the textbook's general organization and structure were not only good, but also similar to several other textbooks.

\section{Activities}

Students' social interactions, according to Vygotsky (1978) and Long (1990), are critical to their learning. The finest sorts of activities, according to Jacobs and Ball (1996), are collaborative learning techniques that enable meaning negotiation and generate positive connection and individual accountability. Long (1990) identified five advantages of interactive group activities, which are listed here: i) Interactive group activities increase quantities of students' language use; ii) it enhances the quality of the language users; iii) it provides more opportunities for individual instruction; iv) it 
provides a less threatening environment to students; and v) it motivates students for learning.

The findings revealed that the most of the teachers among respondents were not happy with the activities and tasks of the textbook. The teachers were of the view that the textbook's activities should be revised and updated. The tasks should be more challenging and creative.

Students, on the other hand, were satisfied with the textbook's activities. The textbook's activities, according to participants, encouraged creative writing and independent replies. One of the possible reasons for such responses is the teaching methodology used in the school of Punjab, Pakistan. Mostly, classrooms in Punjab, Pakistan, are teacher-centred. Learning in such schools depends upon drilling, memorization and the audio-lingual method. When students compare the teacher-centered approach to the activities given in the textbook, they clearly prefer the textbook.

A detailed examination of the textbook's activities and tasks revealed a cramming-based approach rather than engaging and strengthening the creative abilities of individual students. It does not insight their cognitive domain. According to Pirzad, Abadikhah and Khonamri (2021), a good textbook should provide opportunities for a higher level of cognitive learning but the textbook does not provide any opportunity for higher levels of cognitive processing such as reasoning and the exchange of information. On the whole, the activities and tasks of the book should be revised according to the needs of the teachers and students. The results of the study are in line with Daneshfar's and Abdollahi's (2018) results.

\section{Skills}

McDonough and Shaw (1997), Swan (1985), and Harmer (1996) three well-known ELT authors, advocated for an interconnected, multi skills syllabus because it evaluates and combines multiple classes of both form and function. Students are always in need of a book that covers all four language skills in a comprehensive manner (Mohammadi \& Abdi, 2014). The study's findings revealed that the textbook under consideration covered both receptive and productive skills. Receptive skills, according to Litz (2001), include engagement 
on the reader's or listener's side, whereas productive skills are concerned with language fluency.

The majority of the respondents (47 respondents) agreed that the evaluated textbookmaintained a reasonable match of all language skills, according to the survey results. The teachers were unanimous in their beliefs that the evaluated textbook promoted/encouraged innate pronunciation. However, most of the respondents belonging to both groups were undecided about the textbook's emphasis on skills like listening and taking notes.

\section{Language Type}

Under this dimension of the questionnaires, respondents belonging to both the groups, teachers and students, were asked to rate the textbook's language whether the language written in the book is authentic or not. It also examined the day to day use of language whether the learners, after studying the language from the book, can apply it in their own situation or not. It means it evaluated the natural part of the language.

Other crucial criteria were whether the English language was at appropriate stage for the appropriate learners and whether the development of the new language was rational and apposite for the learners. Most importantly, how and in what sequence learners are supposed to learn a new language. In short, we would want students to be able to make a discernible link or connection between what they have learned yesterday and what they are learning today.

The evaluated textbook emphasises the grammatical accuracy of words and sentences, as well as the repetition or recycling of forms and functions, in terms of grammatical structures and functions. Correct knowledge of grammar and functions, according to the writer, are important components of communicative ability.

The means of both the questionnaires, one belonging to teachers and the other belonging to students, were a bit different in terms of the authenticity of the language. The mean of the students' questionnaire on this topic was 3.56, whereas the mean of the teachers' questionnaire was 3.35 on this point. According to the statistics of the study, the examined textbook had both 
authentic and inauthentic content (language). It might be regarded as a textbook advantage because it keeps the book from being too challenging or too easy for the students. On the whole, the current study findings are in line with Mohammadi and Abdi's (2014) study results.

\section{Subject and Content}

Language, according to Kramsch (1994) and Grabowska and Kwadrans (2020), is an element of culture. It means that one cannot learn a language without first learning about culture (Nguyen, 2017; McDonough \& Shaw, 1997). Language instruction and culture are inextricably linked to each other. These criteria alone demonstrate that an authentic representation of the target language culture should be a basic criterion for ELT textbooks (Litz, 2001).

The participants were asked about the subject relevancy and the contents of the graded textbook in this section of the questionnaires. They were questioned regarding the magnitude of its ideas and subject matter. They were also questioned on the variety of issues covered. The researcher also asked about the textbook's negative portrayal of anything or any form of stereotype.

The evaluated textbook contains numerous intriguing contemporary subjects and themes in terms of subject representation and cultural substance. It covers a wide range of religious issues, customs, traditions, and recreational stories. All of these components add to the book's appeal to both teachers and students. Furthermore, the findings of the study show that the textbook does not reflect any preconceptions or biases based on ethnicity, race, creed, class, or colour. It presents such characters, which are realistic in nature; even a few of them are taken from Islamic history.

The majority of respondents were of the view that the textbook offered a wide range of topics that were fascinating, challenging, and encouraging. This textbook broadens students' overall knowledge, understanding and experiences by introducing them to the different perspectives of another culture, according to poll respondents. Most of the respondents belonging to the teachers' group were adamant that the materials were not culturally prejudiced and did not promote any bad/negative stereotypes. Despite this, the majority of the students were in accord. 


\section{Overall Consensus}

In this part of the questionnaires, both the students and teachers were asked about the appropriateness of the textbook according to the needs of the institutions, raising of students' interest, and reusing the book.

\section{Table 2}

Summary of the Responses Regarding Overall Consensus

\begin{tabular}{llll}
\hline Sr. No. & Question & Teachers & Students \\
\hline 18 & $\begin{array}{l}\text { The textbook is appropriate for the } \\
\text { language-learning aims of my institution. }\end{array}$ & ${ }^{*} \mathrm{~A}$ & - \\
$19-14$ & $\begin{array}{l}\text { The textbook raises my (students') } \\
\text { interest in further English language study. }\end{array}$ & $* \mathrm{~A}$ & $*$ SA \\
$20-15$ & $\begin{array}{l}\text { I would choose to teach/read this } \\
\text { textbook again. }\end{array}$ & $* \mathrm{~A}$ & $* * \mathrm{SA}$ \\
\hline
\end{tabular}

Note: * A = Agree, ${ }^{* *}$ SA = Strongly Agree

\section{CONCLUSION}

The current study looked at a 10th-grade textbook published by the Punjab Curriculum and Textbook Board in Lahore and utilised in both private and public schools across Punjab, Pakistan. It weighed the benefits and drawbacks of the textbook in order to determine its genuine value. Overall, it was found that the positive features outnumbered the negative ones by a large margin. Despite several problems in the book, like the lack of a glossary list and presentation of the grammar, the teachers believed the 10th grade textbook was adequate for the achievement of educational objectives and would use it afterwards. It also piqued the interest of students in continuing their language studies.

The evaluated textbook, Punjab Curriculum and Textbook Board Lahore's 10th-grade textbook, is a relatively new and updated addition to the huge assortment of English Language Teaching (ELT) resources available in the market. The textbook as a whole is well-designed, and it includes a great deal of valuable additional information. The book is also visually appealing and organised in a coherent, consistent, and orderly manner. Receptive and 
productive skills, in particular, are taught through different practical learning and teaching methodologies that are congruent with several of SLA's key concepts. Lexical skills are further addressed using a number of dependable strategies like graphic devices, which should aid learners in assigning meaning and storing words and expressions in their permanent reminiscences. According to Brown and Yule (1983), it is hard to find items that will pique everyone's interest. All in all, the evaluated textbook is appropriate for both students and teachers.

This textbook can be recommended in this specific study environment, and with a few tweaks, it can be a useful textbook in the hands of both professional teachers and good students. As a result of $10^{\text {th }}$ grade textbook examination, it is intended that language specialists would get a better understanding of how to implement this technique in their own situations. The study findings advocate that author(s) of the textbook should include more fundamental elements in their EFL/ESL textbooks while still tailoring and modifying them to the needs of learners through the use of appropriate evaluations and surveys. Many of the characteristics of a truly substantial textbook are occasionally lacking in textbooks that appear to be sound on the surface. As a result, people who are making these decisions must thoroughly study all components of the text and compare them to an evaluation instrument. An evaluation checklist/survey, whether created by the researcher or adapted from another source, helps to focus this investigation and makes sure that crucial topics are not neglected (Soori, Kafipour \& Soury, 2011).[rgt]

\section{REFERENCES}

Aqel, A. R. A. Q. M. (2009). An evaluative study of the Palestinian 11th grade English textbook from the teachers' perspective in Southern Nablus and Salfit Districts (Doctoral dissertation).

Ayu, M., \& Indrawati, R. (2019). EFL textbook evaluation: The analysis of tasks presented in English textbook. Teknosastik, 16(1), 21-25.

Badawi, M. (2007). Studies in Curriculum \& Instruction. Tabouk Teacher' College, Kingdom of Saudi Arabia. 
Brown, G., \& Yule, G. (1983). Discourse analysis. Cambridge University Press.

Crawford, J. (1995). The role of materials in the language classroom: Finding the balance. TESOL in Context, 5(1), 25-33.

Cunningsworth, A. (1995). Choosing Your Coursebook. Heinemann.

Daneshfar, S., \& Abdollahi, J. (2018). Textbook evaluation: A case study of Iranian teacher and student perspectives. International Journal of English Literature and Social Sciences, 3(3), 450-456.

Fukkink, R. G. (2010). Missing pages? A study of textbooks for Dutch early childhood teacher education. Teaching and Teacher Education, 26(3), 371-376.

Grabowska, B., \& Kwadrans, L. (2020). Language as an element of identity: language of national minorities in the educational systems of Belarus, the Czech Republic, Poland, and Ukraine.

Hargreaves, A. (1989). Curriculum and assessment reform. OISE Press.

Harmer, J. (2001). The practice of English language teaching. London/New York, 401-405.

Hutchinson, T., \& Torres, E. (1994). The textbook as agent of change.

Jacobs, G. M., \& Ball, J. (1996). An investigation of the structure of group activities in ELT coursebooks. ELT Journal, 50(2), 99-107.

Kurkgöz, Y. (2009). Evaluating the English textbooks for young learners of English at Turkish primary education. Procedia-Social and Behavioral Sciences, 1(1), 79-83.

Kramsch, C. (1993). Context and culture in language teaching. Oxford university press.

Litz, D. R. (2005). Textbook evaluation and ELT management: A South Korean case study. Asian EFL journal, 48(1), 1-53.

Long, M. H. (1990). Task, Group, and Task-Group Interactions.

Mahmood, A., Butt, M. I., \& Mahmood, S. (2021). Textbook Evaluation: Analyzing English Textbook I of Federal Board at SSC Level in the Light of Bloom's Taxonomy of Educational Objectives. Hayatian Journal of Linguistics and Literature, UOG, 91. 
Marc, V., \& Rees, K. (2009). Literary education curriculum and institutional contexts: Textbook content and teachers' textbook usage in Dutch literary education, 1968-2000. Poetics, 37(1), 74-97.

McDonough, J., \& Shaw, C. (2012). Materials and Methods in ELT. John Wiley \& Sons.

Mohammadi, M., \& Abdi, H. (2014). Textbook evaluation: A case study. ProcediaSocial and Behavioral Sciences, 98, 1148-1155.

Nguyen, T. (2017). Integrating culture into language teaching and learning: Learner outcomes. The Reading Matrix: An International Online Journal, 17(1), 145155.

Pirzad, F., Abadikhah, S., \& Khonamri, F. (2021). Textbook Evaluation and Teachers' Perceptions of Task-Based Language Teaching: A Case of Iranian Bilingual Schools. Research in English Language Pedagogy, 9(1), 113-134.

Ponnusamy, N. K., Sandaran, S. C., \& Gunasegaran, I. (2021). Evaluation of Year 6 KSSR English (SK) Textbook: Teachers' Perspectives. LSP International Journal, 8(1), 67-80.

Rahim, M. N., Mohammadi, T., \& Hashemi, A. (2021). A Critical Evaluation of the Twelfth Grade English Language Textbook for Afghanistan High Schools. Elsya: Journal of English Language Studies, 3(2), 67-77.

Razmjoo, S. A. (2007). High schools or private institutes textbooks? Which fulfill communicative language teaching principles in the Iranian context. Asian EFL Journal, 9(4), 126-140.

Rea-Dickens, P. \& Germaine, K. (1992). Evaluation. Oxford: Oxford University Press.

Romero, R. (1975). What textbook shall we use. In English Teaching Forum (Vol. 13, No. 3, p. 4).

Serasi, R., Fatimah, L., Hakim, M. A. R., \& Anggraini, D. (2021). A Textbook Evaluation On English Textbook Entitled "Grow With English" Used By Students Of MI Nurul Huda Bengkulu City. Al-Lughah: Jurnal Bahasa, 10(1), 21-31.

Sheldon, L. E. (1988). Evaluating ELT textbooks and materials. ELT Journal, 42(4), 237-246.

Soori, A., Kafipour, R., \& Soury, M. (2011). EFL textbook evaluation and graphic representation. European Journal of Social Sciences, 26(3), 481-493. 
Suhirman, L. (2018). ESP Textbook Evaluation: English for Islamic Learning for College Students. IJOTL-TL: Indonesian Journal of Language Teaching and Linguistics, 3(1), 13-22.

Surtikanti, M. W. (2020). Textbook Evaluation on Curiculum 2013-Based Textbook "When English Rings A Bell" for the Seventh Grade.JOEEL: Journal of English Education and Literature, 1(1), 11-17.

Swan, M. (1985). A critical look at the communicative approach (1). ELT Journal, 39(1), 2-12.

Vygotsky, L.S. (1978). Mind in Society. Harvard University Press. 
This page has been intentionally left blank. 